\title{
O FUNCIONAMENTO DA MEMÓRIA DISCURSIVA E O EQUÍVOCO NA PRÁTICA AVALIATIVA DE LÍNGUA INGLESA $^{1}$
}

\author{
WAGNER ERNESTO JONAS FRANCO2
}

Instituto de Estudos da Linguagem, Universidade Estadual de Campinas

Rua Sérgio Buarque de Holanda, 571 - Cidade Universitária, Campinas - SP, 13083-859

dominiumwagnereyahoo.com.br

\begin{abstract}
Resumo. O objetivo deste estudo é compreender o funcionamento da memória discursiva em uma prática avaliativa de língua inglesa aplicada em uma sala do segundo ano do ensino médio noturno de uma escola regular pública de Pouso Alegre-MG. O embasamento teórico-metodológico utilizado é o da Análise de Discurso de orientação pecheuxtiana. Em nossa análise, percebemos que os gestos de interpretação do sujeito-aluno diante do texto da avaliação são atravessados pelo equívoco constitutivo do sujeito e da linguagem: diferentes sentidos são atribuídos ao mesmo material simbólico; sentidos que são silenciados pelo professor. Concluímos que um trabalho significativo com a língua envolve a dimensão da memória, do saber discursivo que é histórico e só faz sentido quando se relaciona ao discurso do sujeito.
\end{abstract}

Palavras-chave: memória discursiva; avaliação; interpretação; Língua Inglesa.

\begin{abstract}
The aim of this study is to understand the functioning of the discursive memory in an English language assessment practice in a class of the second year of high school in a regular public school in Pouso AlegreMG. The theoretical-methodological basis used is the Discourse Analysis as thought by Michel Pêcheux. In our analysis, we realized that the interpretation gestures by the subject-learner before the text of the evaluation is crossed by constitutive misunderstanding of the subject and the language, different meanings are assigned to the same symbolic material, senses that are silenced by the teacher. We conclude that a significant work with the language involves the memory, discursive knowledge that is historical and only makes sense when it relates to the subject's discourse.
\end{abstract}

Keywords: discoursive memory; evaluation; interpretation; English Language.

\footnotetext{
${ }^{1}$ Este artigo é um recorte de minha dissertação de mestrado defendida no Programa de Pós-graduação em Ciências da Linguagem na Universidade do Vale do Sapucaí em Pouso Alegre - MG, no ano de 2015, sob

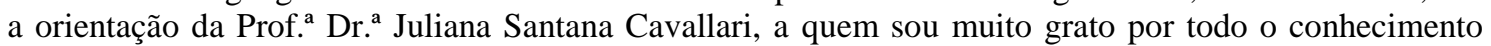
partilhado.

${ }^{2}$ Doutorando em Linguística na Unicamp. http://lattes.cnpq.br/1358368751883381.
} 


\section{Introdução}

Este trabalho tem por objetivo investigar o funcionamento da memória discursiva na resolução de uma avaliação bimestral escrita de língua inglesa, em uma sala do segundo ano do ensino médio noturno de uma escola pública municipal em Pouso Alegre - MG. Buscamos subsídios teórico-metodológicos na Análise de Discurso de orientação pecheuxtiana, disciplina de entremeio que considera a língua como sistema relativamente autônomo, incompleta, heterogênea, sujeita a falhas, ao equívoco, que significa historicamente, numa relação com o sujeito e a ideologia.

Trataremos do funcionamento da memória, entendida discursivamente como interdiscurso, "saber discursivo que torna possível todo dizer" (ORLANDI, 2010, p. 31), na prática avaliativa formal em língua estrangeira (inglês) e em sua relação com a língua materna entendida como matéria fundante do psiquismo, que não pode ser excluída ou totalmente apagada do processo de aprendizagem de línguas.

Para discutir o processo de ensino-aprendizagem de língua estrangeira, na atualidade brasileira, em que o ensino de língua inglesa apresenta diversas questões que intrigam pesquisadores, professores e alunos, tomaremos como corpus a avaliação escolar, instrumento amplamente utilizado para averiguar o desempenho dos estudantes em diversos níveis. A prática avaliativa é comum a todas as disciplinas, mas o professor de línguas, particularmente o de inglês, por trabalhar com a linguagem, deve ter uma atenção especial ao funcionamento de sua avaliação.

Neste trabalho de pesquisa, os instrumentos avaliativos analisados não são os oficiais externos (PAAE, SIMAVE, Enem ${ }^{3}$ ), geralmente elaborados por especialistas dos órgãos governamentais e direcionados para as escolas, prontos para serem aplicados pelo professor. Refiro-me às avaliações internas elaboradas pelos próprios professores.

Tendo em vista que os alunos do segundo ano do ensino médio da referida escola - em grande parte socioeconomicamente desfavorecidos - possuem pouco conhecimento e contato com a língua inglesa (LI) e esse conhecimento revela uma noção de língua enquanto sistema que se encerra em si mesmo, levantamos a seguinte hipótese: professores e alunos possuem noções de língua distintas, além de uma relação singular com a linguagem, o que afeta a relação ensino-aprendizagem e as práticas avaliativas e produz equívocos nas respostas e interpretações; equívocos esses que não costumam ser trabalhados por professores e alunos, mas sim apagados, silenciados, já que a língua é geralmente representada, no contexto escolar, como algo neutro e passível de ser instrumentalizável.

A avaliação que tomamos como material de pesquisa traz um texto em inglês com perguntas referentes a ele em português e em inglês. Os alunos podem optar por responder a essas perguntas em português ou em inglês (orientação dada a eles com antecedência). Trata-se de uma avaliação da compreensão escrita do aluno, a partir do texto apresentado

\footnotetext{
${ }^{3}$ PAAE: Programa de Avaliação da Aprendizagem Escolar; SIMAVE: Sistema Mineiro de Avaliação da Educação Pública; Enem: Exame Nacional do Ensino Médio.
} 
em LI. Como desdobramentos da hipótese apresentada acima, formulamos as seguintes questões que irão ancorar a análise dos registros discursivos:

- Quais representações de língua inglesa são reveladas pelas respostas dos alunos em uma avaliação escrita de língua inglesa?

- Como se dá o funcionamento da memória em língua materna e estrangeira na compreensão de uma avaliação escrita de língua inglesa?

O conceito de representação que adotamos neste trabalho opõe-se a uma concepção positivista do termo, segundo a qual a representação seria uma apreensão do real, portanto única e homogênea. Com base em Hall (1997) e Grigoletto (2003), enfatizamos a dimensão de significante da representação como uma construção imaginária do real e, consequentemente, de forma(s) de atribuição de sentido. Junto a isso, acrescentamos que o conceito de representação, aqui adotado, se aproxima do conceito de Formação Imaginária proposto por Pêcheux (1969).

Feitas estas considerações iniciais, apresentamos a seguir os conceitos norteadores deste trabalho, quais sejam o de memória discursiva e equívoco, assim entendidos pela Análise de Discurso. Em sequência, apresentamos a avaliação aplicada e cujas respostas compõem o corpus desta pesquisa para, então, realizarmos nossa análise. Por fim, delineamos algumas conclusões a que chegamos.

\section{Algumas noções: sobre a memória discursiva e o equívoco}

Neste trabalho, abordaremos a memória discursiva a partir das contribuições de Payer (2006) sobre como a repetição leva à inscrição de memória na língua. A memória, para a autora, está ligada à repetição, ao "reconhecimento do mesmo" (PAYER, 2006, p. 38), ou, em outras palavras, a forma de um objeto físico do mundo ou de uma emissão sonora (palavra), repetidos, transformam-se/inscrevem-se enquanto matéria reconhecida, imagem significada, na língua.

A autora ressalta que, na própria construção da língua, enquanto produção humana e sócio-histórica, a memória trabalha e é trabalhada porque há repetição. Nesta forma de constituição de memória, a autora procede a duas distinções: a memória na língua e a memória da língua, pensando língua e memória em aspectos discursivos. Essas distinções podem ser entendidas como pontos de vista ou, como a própria autora diz, "deslocamentos de olhar" (p. 39) na relação língua e história. A língua constitui a história e a história está marcada na língua. Expliquemos melhor a seguir, retomando as palavras da autora.

A memória na língua diz respeito ao

modo como os sentidos produzidos e sustentados socialmente, pela repetição, se encontram nisto que chamamos de língua já em seus elementos mínimos. Nesta perspectiva, podemos compreender que o modo como uma sociedade, um povo, produz sentidos historicamente encontra-se marcado em sua linguagem, no modo como ele fala a "sua" 
língua, ou melhor, a língua que lhe é dado falar por sua história. (PAYER, idem, p. 39)

A memória na língua marca uma historicidade presente na língua. A relação entre memória e língua é vista, neste caso, "a partir do ângulo da memória histórica, sob a forma da memória discursiva, presente na língua” (p. 39). Payer (idem), em seu estudo sobre a imigração italiana ocorrida no Estado do Espírito Santo no momento inicial da instauração da República no Brasil, considera que a língua é parte do "arquivo" histórico de um povo, história que significa através da língua. Compreender sua língua é compreender sua história.

A memória da língua é tomada a partir da língua em sua relação de significação com a história. Ela implica um sujeito/cidadão e os diferentes modos de fazer sua língua "significar" por sua história. É a história fazendo a língua significar.

Essas duas novas formas de compreensão da memória discursiva ampliam nossa visão sobre a mesma. Ao transferir para o contexto escolar, podemos pensar nos aspectos históricos que constituem a memória do aluno e que são refletidos em sua língua. Ou, a partir da língua, apreender vestígios da concepção de linguagem do aluno e do professor e as formas como essa linguagem significa. No ambiente escolar, principalmente na situação de realização de avaliação, a memória na/da língua do aluno pode nos fornecer pistas de como ele compreende a relação língua, história e escola.

Pois, é esta compreensão da relação da memória com a língua na escola que nos impulsiona nesta pesquisa: objetivamos investigar os traços de memória(s) discursiva(s) que se materializam nas respostas dos alunos à avaliação proposta. Respostas que surgem, a princípio, aleatórias, absurdas, desconexas, marcadas, sobretudo, pelo equívoco, mas que, sob o olhar discursivo, revelam representações de línguas (materna e estrangeira) e concepções de ensino- aprendizagem resultantes do contato-confronto com uma língua estrangeira. Central para esta parte do nosso trabalho, o conceito de equívoco será aprofundado a seguir.

Para Milner (2012), quando se pensa a unicidade e distintividade de uma língua, constituída como objeto da linguística, o equívoco trata da dimensão do não idêntico de uma locução, é o que marca o não todo da língua e que permite uma locução ser, ao mesmo tempo, ela mesma e uma outra: "trata-se de tudo aquilo que sustenta o duplo sentido e o dizer em meias palavras" (MILNER, 2012, p. 17). Para o autor, o equívoco é o que escapa a toda tentativa de cerceamento da língua, ou de homogeneizá-la de forma racional e lógica.

Segundo este mesmo autor, a linguística, para se constituir como ciência que estuda uma língua, precisa matematizá-la, torná-la calculável, concebê-la em uma "isotopia absoluta: de qualquer ponto que se a considere, ela [a língua] deveria oferecer uma mesma fisionomia" (p. 20). Em outras palavras, ela precisa ser a mesma para todos os falantes, homogênea, una. Milner (idem) diz que a língua, para ser objeto de uma escrita científica, deve ser unívoca, sempre idêntica a si mesma e para tanto, as seguintes proposições devem ser descartadas: "as línguas, por serem incomensuráveis, não formam uma classe consistente; uma língua não é idêntica a si mesma; uma língua não é uma 
substância; uma língua pode cessar de ser estratificada; uma língua não é isótopa” (p. 20). Logo, o que fica de fora é da ordem do equívoco, do não apreensível da língua.

Motta e Turra (2014), ao tecerem considerações a respeito do que propõe Milner, trazem que:
É justamente pela via desse inapreensível [o equívoco] que Lacan se aproxima da linguística e, para escrevê-lo, não tenta conceitualizá-lo, objetificá-lo. É a partir de um lapso seu durante uma de suas aulas, que Lacan trabalha com o extrínseco da linguística: lalangue, assim, em uma palavra, "é, em toda língua, o registro que a fada ao equívoco". Desse modo, "falar de língua e de partição é reconhecer que não se pode dizer tudo. Dito de outro modo, o puro conceito de língua é o de um não todo marcando lalíngua; ou ainda, a língua é o que sustenta lalíngua na qualidade de não toda". (MOTTA; TURRA, 2014, p. 3)

Isso posto, percebemos, em nosso corpus, dizeres que vão ao encontro dessa impossibilidade de dizer tudo, da não univocidade da língua que a impede de ser entendida da mesma forma por falantes diferentes, ou seja, como instrumento que visa apenas à comunicação.

Para melhor compreensão, reproduzimos abaixo o modelo da avaliação aplicada na referida sala com o gabarito de referência utilizado pelo professor. A prova foi aplicada no dia 6 de junho de 2014, das 19h às 19 h50 para 22 alunos. A aplicação ocorreu dentro da normalidade, sem nenhuma interrupção, houve tempo suficiente, nenhum aluno usou de qualquer artifício ilegal para se beneficiar na prova. Ao final da aula, todos entregaram a avaliação sem queixas ou comentários.

ESCOLA MUNICIPAL
Name:
Value: $7,5 \quad$ Score:
Responda às questões de acordo com o texto.
Taking the risk
Sports World maganize recently spoke with Jenny Adams, Tom Barker, and Ray
Lee about risky sports.
Have you ever had an accident?
Jenny: No, I've never been hurt. Maybe I've been lucky. Sometimes the wind can
be too strong. Once, my glider turned upside down and I almost crashed, but I parachuted
away just in time. Actually, I've always felt that hang gliding is very safe. And it's
amazing to be able to fly like a bird.
SW: Tom, you've been mountain climbing for years now. What are some of the
dangers you've experienced?
Tom: When you're high up on a mountain, the conditions are hard on the human
body. The air is thin, and you get tired. I've lived through storms and bad weather. But I
like the challenge and I like overcoming danger. That's why I do it.
SW: Ray, have you ever experienced any danger while scuba diving?


from

Ray: Luckily, I haven't. But people can get the bends if they come up too quickly

deep under water. Bubbles form in the blood. The bends can be serious, and can even cause death. But the condition is rare. Diving isn't really that dangerous. And the great thing is that it lets you explore another world.

Fonte: Interchange, Third Edition, 2006, p. 69

Vocabulary: glider: planador - parachute: saltar de paraquedas - challenge: desafio overcome: superar - bend: bolhas no sangue - death: morte - dive: mergulhar - wind: vento - danger: perigo - quickly: rápido

1) Escreva o nome dos esportes mencionados no texto na figura correta:

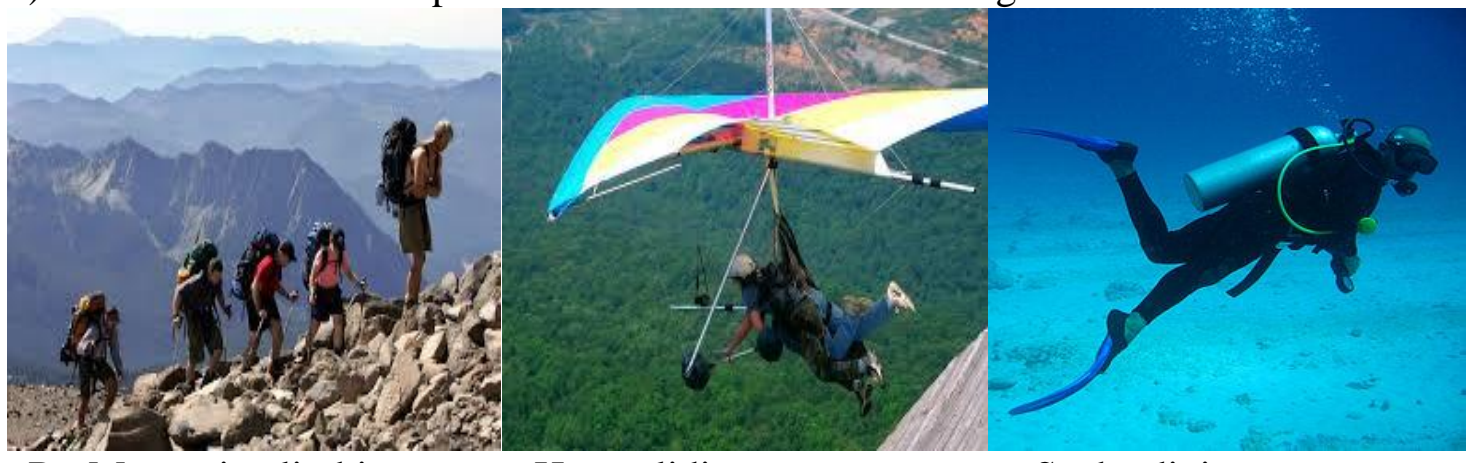

R: Mountain climbing

Hang gliding

Scuba diving

2) What sport does Jenny practice? R: She practices hang gliding.

3) Why does she like it? R: She finds amazing to be able to fly like a bird.

4) What is the danger about this sport? R: Sometimes the wind can be too strong.

5) Has Jenny ever had an accident? R: Once, her glider turned upside down and she almost crashed.

6) What sport does Tom Practice? R: He practices mountain climbing.

7) What does he enjoy about this sport? He likes the challenge and overcoming danger.

8) What are the dangers about this sport? R: When you're high up on a mountain, the conditions are hard on the human body. The air is thin, and you get tired.

9) Has he lived through storms and bad weather? R: Yes, he has.

10) What sport does Ray practice? R: He practices scuba diving.

11) Has he ever experienced any danger while scuba diving? R: No, he hasn't.

12) What is the danger about this sport? R: People can get the bends if they come up too quickly from deep under water. Bubbles form in the blood. The bends can be serious, and can even cause death.

13) Why does he like it? R: He likes it because diving lets you explore another world.

14) O pronome it na última frase do texto refere-se a qual palavra? Scuba diving.

15) De acordo com Tom, o que provoca o cansaço nas pessoas quando elas estão no alto da montanha? R: The thin air.

Figura 1. Modelo de avaliação com resposta. 


\section{O equívoco nas respostas dos alunos e o funcionamento da memória discursiva}

Apresentamos, a seguir, alguns equívocos relacionados à compreensão das imagens, no primeiro exercício da prova acima.

$\mathrm{Na}$ referida questão, sete alunos responderam de acordo com a resposta prevista no gabarito, os outros quinze alunos se aproximaram desta resposta. Dos vinte e dois alunos que realizaram a prova, dois escreveram a resposta completa - o nome dos esportes - em língua portuguesa, sendo que um aluno teve a resposta considerada correta.

Percebe-se, como regularidade, nas respostas às questões, de modo geral, e nesta primeira, em particular, uma forte determinação da memória discursiva da língua materna que constitui o sujeito-aluno, da qual ele se encontra impossibilitado de se desvencilhar, sendo esta memória de estatuto diferente da memória discursiva da língua estrangeira, que não se recobrem, e o sujeito-aluno lança mão destas memórias tecidas em rede para solucionar a avaliação que a ele é solicitado. Estas memórias, enquanto regiões de sentido, feitas de esquecimento, ditam um conhecimento sobre as línguas, materna ou estrangeira, incluindo aí as regras sobre estas línguas.

Nas respostas redigidas em português, a memória discursiva da língua materna do aluno é marcada pelo sentido colado à palavra, pela literalidade e equivalência entre as línguas, como se fosse possível uma tradução termo a termo de todas as palavras de uma língua para a outra. Essa marcação também é percebida na tentativa do aluno de recorrer ao vocabulário de ajuda fornecido ao final da prova para que ele dê sua resposta em inglês. O recorte discursivo (RD) abaixo ilustra melhor esta nossa colocação:

RD1: Respostas dos alunos à primeira questão:

Aluno 1: montanhista/ asa delta/ mergulhador

Alunos 2 e 3: mountain/ glider/ dive

Alunos 4, 5, 6: mountain/ parachuted/ dive

Aluno 7: monteismo/ paraquedista/ mergulhador

Aluno 8: up on a mountain/glidered/ under water

Aluno 9: high up on a mountain/ glider/ dive

O recorte acima reproduz diferentes respostas dos alunos a um mesmo exercício, diferentes palavras para descrever uma mesma imagem, marcando o equívoco constitutivo da linguagem. Ao serem solicitados para escreverem o nome dos esportes mencionados no texto, os alunos 1 e 7 recorrem à língua materna para darem as suas respostas e o fazem descrevendo o que interpretam nas imagens, em uma relação direta linguagem $\rightarrow$ mundo, sentido colado à palavra. Ao descreverem apenas o que interpretam nas imagens, os alunos parecem não as vincular à leitura do texto, talvez por não terem compreendido os respectivos esportes descritos em língua inglesa, optando, desta forma, pelas respostas em língua portuguesa. 
Ao responderem em língua materna, os alunos demonstram conhecer os respectivos esportes: montanhista é aquele que pratica montanhismo, asa delta é o principal equipamento para a prática do voo livre, esporte que às vezes leva o nome deste próprio equipamento, o aluno 7 fornece a resposta paraquedista aquele que pratica o paraquedismo (esporte não mencionado no texto) e mergulhador é aquele que pratica mergulho. Mas, não se pode afirmar que os alunos chegaram a estas respostas através da leitura do texto, caso contrário, talvez teriam escrito em inglês ou o nome do próprio esporte em português.

Cabe observar que, ao levarmos em conta os gestos de interpretação dos alunos e o equívoco constitutivo da linguagem, nenhuma das respostas dadas acima estaria totalmente errada ou desvinculada das imagens apresentadas ou da resposta que foi antecipada pelo professor como sendo a resposta correta. De algum modo, todas as respostas fornecidas podem ser associadas à prática dos esportes ilustrados nas/pelas figuras.

Sobre essa multiplicidade do dizer, cabe a observação de Ferreira (2000, p. 27): "Os sentidos ambíguos, a apreensão de equívocos na fala [e, acrescentamos, na escrita] não podem ser imputados a problemas episódicos de interpretação, mas sim a condições estruturantes da própria língua". Não houve, portanto, uma interpretação errônea por parte do sujeito-aluno, mas gestos de interpretação próprios à ordem do simbólico, do dizer que é sempre múltiplo.

Vale salientar que o gabarito também exerce a função de antecipar as respostas e os sentidos tomados como verdadeiros e/ou ideais, por parte daquele que tem o poder de avaliar o saber do aluno; no caso: o professor.

As respostas destes alunos não demonstram apenas que estes desconhecem o vocabulário em língua estrangeira, mas também denunciam práticas escolares simplistas de ensino de línguas ainda comuns, como:

a) O trabalho com o vocabulário descontextualizado, com exercícios para relacionar as imagens ou definições de palavras e frases, que se fundamentam na ilusão de que há uma relação direta entre significante e significado, e que nos remetem a práticas defendidas pelo Método Audiolingual.

b) O ensino de línguas, principalmente a estrangeira, não se baseia na leitura e compreensão de textos. Quando estes são trabalhados, em sala de aula, o aspecto (inter)discursivo, a memória discursiva que atua na produção de sentidos sóciohistoricamente legitimados é deixado de lado. Portanto, a memória que define a direção dos sentidos e que é fundamental para a compreensão do texto, é a memória que remete aos exercícios estruturais, que compreende a língua como estrutura que se encerra em si mesma.

As outras respostas, embora tenham sido formuladas em língua inglesa, também são fortemente marcadas pela memória da língua materna, mais especificamente, 
reconhecemos traços de uma memória na língua, assim pensada por Payer (2006), esta é uma memória histórica que se presentifica na língua, já em seus elementos mínimos.

Percebemos a presença dessa memória no emprego, que os alunos fizeram, das palavras mountain (montanha) e dive (mergulhar). A palavra mountain é cognata, parecida com sua tradução em língua portuguesa; portanto, de fácil reconhecimento por parte do aluno, mas, em si, mountain não traz a resposta considerada correta, porque não descreve o esporte a que a imagem se refere. No entanto, podemos dizer que é um préconstruído, já constituído em memória, que leva o aluno a escrever mountain na resposta. Esse pré-construído diz que uma palavra em inglês pode ter vários sentidos, podendo ser, ao mesmo tempo, um verbo e um substantivo, ou um verbo e um adjetivo ou que uma palavra não possui uma tradução literal (como os estrangeirismos shopping, outdoor) ou que uma palavra em inglês pode precisar de uma locução ou um enunciado inteiro para ter seu sentido traduzido para a língua portuguesa. Trazemos, aqui, esse pré-construído porque acreditamos que ele é muito utilizado por professores para descrever a língua inglesa; os alunos, portanto, são levados a acreditar que as características citadas acima são referentes apenas a esta língua e não são aplicadas a todas as línguas ou à própria língua materna, acreditando que a sua língua é homogênea, clara e transparente.

A palavra mountain, na prova, descreve, então, montanha, mas também o esporte a que se refere: montanhismo. O uso de mountain denota um certo contato do aluno com o texto, porque dele retira a palavra. A mesma memória atua no aluno ao escrever na prova dive, uma palavra que consta no vocabulário de ajuda - glossário - fornecido ao final do texto. Dive significa o verbo "mergulhar" ou o substantivo "mergulho" enquanto "salto de cabeça para baixo" (Michaelis, online). Mas, o esporte mergulho, em inglês, é escrito diving ou Scuba diving. Podemos nos perguntar por que os alunos não empregam, nas suas respostas, simplesmente as palavras em português montanha ou mergulhar, e, como possível resposta, dizemos que estas palavras não indicam a resposta padrão esperada pelo professor; o aluno, então, recorre à língua inglesa para aproximar a sua resposta do que é esperado pelo professor, acreditando, talvez, não conscientemente, que a palavra dive possa designar, também, o esporte mergulho.

O mesmo podemos dizer das palavras glider, glidered, under water, e parachuted, palavras que constam no glossário da prova ou foram retiradas do texto com pouca ou nenhuma modificação na estrutura. Estas palavras apontam para uma memória na língua porque pode ser reconhecida nelas a presença de uma memória constituída historicamente sobre o que é língua materna/portuguesa ${ }^{4}$ e define a constituição dos sentidos. Estas respostas demonstram a relação singular do aluno com a língua estrangeira, a forma como ele é afetado por ela.

Segundo Cavallari (2005), em situação de avaliação, o aluno que recorrer à língua materna será avaliado negativamente pelo professor, pois este acredita que o aluno "estará degenerando ou deturpando o processo de ensino-aprendizagem de LI, sempre que utilizar sua língua primeira que, neste contexto [de avaliação], ocupa uma posição hierárquica pior ou inferior em relação à LI, já que não é objeto de desejo" (p. 166). Por

\footnotetext{
${ }^{4}$ Reconhecemos que há diferenças e especificidades entre as noções de língua materna e de língua portuguesa, mas não adentraremos essas questões, por não serem objeto deste trabalho.
} 
essa razão, o aluno recorre, também, à língua inglesa em suas respostas, na tentativa de formular uma resposta que seja bem avaliada pelo professor. Resposta que talvez não consiga ser formulada pelo aluno em sua língua materna.

Duas outras respostas, deste mesmo recorte discursivo, chamam-nos a atenção pela particularidade de suas construções: up on a mountain e high up on a mountain. Não é apenas uma ou duas palavras que o aluno emprega para designar o esporte que o exercício solicita, mas quatro ou cinco. Ao olharmos para essas construções no texto, vemos que elas se delimitam, de um lado, pelo sujeito e verbo you're e, de outro, pela vírgula, que funciona como a pausa para uma nova ideia. You're (você é/está) é parte de dois tópicos gramaticais exaustivamente trabalhados em sala de aula de língua inglesa: subject pronoun e verb to be. Os alunos 8 e 9 não empregam you're em suas respostas, porque, de certa forma, sabem que não é disso que se trata no exercício. Entre you're e mountain, a memória discursiva preenche a lacuna. (high) up on a funciona como um verbo (escalando?). Se o aluno entendeu que é um esporte que precisa ser escrito e escrever apenas mountain seria escrever montanha, um imaginário de língua inglesa lhe permite escrever (high) up on mountain, uma língua que se diferencia da sua primeira em termos de estrutura.

Nas outras questões, também podemos perceber respostas que denunciam a forte influência da língua materna na compreensão do texto em língua estrangeira, juntamente com a atuação da memória sobre o que é uma língua estrangeira, neste caso, a língua inglesa:

RD2: Em referência à pergunta 2) What Sport does Jenny practice? (Que esporte Jenny pratica?). Resposta esperada pelo professor: She practices Hang gliding. (Ela pratica voo livre.)

Aluno 10: She practice in the glider turned upside down

Aluno 11: Is a dangerous sport.

Aluno 1, 3: Parachute

Alunos 4, 12, 7: parachuted $^{5}$

Aluno 5: Jenny salta de paraquedas ${ }^{6}$

Destacamos a ação da memória na língua no uso de practice, que, de acordo com a gramática normativa do inglês deve-se acrescentar o "s" à terceira pessoa do singular no presente simples e em Is, onde seria It is; estas construções são feitas em inglês, mas obedecendo às regras da estrutura do português. Uma memória discursiva de sentidos sobre o que é língua estrangeira é percebida em Parachute, que, para o aluno, designa o esporte "saltar de paraquedas". Em parachuted, o aluno transcreve a palavra como consta no texto. Nota-se que esta palavra está no passado simples do inglês (Simple Past), um tópico gramatical que consta nos materiais didáticos adotados em sala de aula, portanto, um tópico recentemente trabalhado pelo professor em sala de aula. Sob o efeito do Discurso Pedagógico autoritário (ORLANDI, 2011), que diz que o aluno precisa

\footnotetext{
5 Os alunos 4 e 7 escreveram, ainda, junto a esta resposta, respectivamente: "(ela gosta de saltar de paraquedas)" e "salta de asa deltas".

${ }^{6}$ Respostas transcritas exatamente como constam nas avaliações.
} 
responder o que o professor quer e exatamente aquilo que foi estudado na escola, o aluno transcreve sua resposta sem se preocupar em modificá-la.

O Discurso Pedagógico de tipo autoritário é, ainda, muito presente na escola e ambos, professor e aluno, estão presos a ele e afetados por ele, principalmente nas práticas avaliativas. Neste discurso em funcionamento, apenas o professor controla os sentidos tidos como verdadeiros ou legítimos e qualquer tentativa, por parte do aluno, de produzir novos sentidos é barrada. Percebemos o funcionamento deste tipo de discurso quando os alunos tentam fornecer respostas que não estão propriamente no texto, mas através dele os alunos chegam a elas, fazendo uma leitura afetada pela memória discursiva, trazendo à tona seus conhecimentos e a maneira como são constituídos pela língua. No entanto, ao realizar este tipo de leitura, os alunos costumam ter suas respostas anuladas pelo professor, por fugirem da resposta padronizada. Exemplo:

RD3: Respostas à pergunta 4) What is the danger about this sport? (Qual é o perigo em relação a este esporte?). Resposta esperada pelo professor: Sometimes the wind can be too strong. (Às vezes o vento pode ser muito forte.)

Aluno 2: cair de uma extrema altura, por isso usa-se o paraquedas. Aluno 3: Wind

Aluno 7: você cair de lá de cima e morrer

Aluno 9: Perigo de bater ou para-quedas, não funcionar

Aluno 11: Perigo de pular de paraquedas e bater ou algo do tipo.

Aluno 13: Paraquedas corre perigo de não abrir.

Todas essas respostas se relacionam entre si e podem ser consideradas como paráfrases que indicam que o aluno realizou uma leitura apropriada da pergunta, ou seja, ele identificou um perigo relacionado ao esporte correto, a saber, voo livre, valendo-se de seu conhecimento de mundo.

Porém, tais respostas não foram aceitas, porque a leitura e a interpretação já estão postas pelo professor e estas se desvinculam de aspectos sociais, históricos, e, até mesmo, subjetivos (no sentido de que envolve a relação singular do sujeito com a língua e com o texto). Para melhor ilustrar nossa colocação, trazemos os apontamentos de Payer (2012) em seu trabalho sobre a questão da leitura e do ritual inscritos no filme Abril Despedaçado (Walter Salles, 2001).

A narrativa do filme citado gira em torno de duas famílias do sertão nordestino brasileiro, à época de 1910, presas em um mesmo universo discursivo: gerações destas famílias matam e morrem em nome da honra, num gesto de vingança, gerado por conflitos de terras já antigos. O filme mostra a repercussão deste ritual de morte na história de vida dos personagens, principalmente em relação ao protagonista Tonho e seu irmão Menino. $\mathrm{O}$ destaque dado ao filme refere-se à sua denúncia do ambiente de extrema pobreza, violência e exploração de trabalho em que os personagens se inserem. 
Payer (idem) diz que os saberes que estruturam este universo discursivo inserem as famílias em uma mesma "formação discursiva", saberes que constituem o em torno destas famílias, a "normalidade", as "evidências" dos sentidos.

A título analítico, a autora toma o acontecimento do absurdo em uma cena do filme, no sentido daquilo que "se opõe à razão e ao bom senso", "o que não se enquadra em regras". A cena em questão é o comparecimento de uma personagem, que é sabidamente o assassino, e sua família ao funeral de sua vítima, expressando condolências à família rival.

A autora tece sua análise a partir de Pêcheux (1999) que, ao falar sobre a relação entre linguagem e ideologia, lembra, a partir de Althusser, que "as práticas ideológicas são aí caracterizadas como 'reguladas' por rituais nas quais as práticas se inscrevem [...]: uma pequena missa em uma pequena igreja, um enterro, um pequeno jogo em uma sociedade esportiva..., etc." (p. 17). E acrescenta: "levar até as últimas conseqüências a interpelação ideológica como ritual supõe o reconhecimento de que não há ritual sem falha, desmaio ou rachadura: uma palavra por outra" (p. 17).

É a partir das colocações acima que Payer pensa o absurdo, na cena descrita anteriormente, como uma rachadura no ritual, um "ponto de resistência", "vindo assim expor o caráter 'falho' do discurso no seio do ritual” (PAYER, 2012, p. 34).

Trazendo as ideias de Payer e Pêcheux para pensar o nosso objeto de pesquisa, podemos considerar a prática avaliativa como um "ritual com falhas", no qual as respostas absurdas poderiam ser consideradas como formas de resistência do aluno a uma dominação ideológica, assim como podemos pensar como resistência ou furos nos rituais, as chamadas $\operatorname{colas}^{7}$, muito comuns em situação de avaliação.

Com propriedade, sobre o caráter falho dos rituais das práticas de linguagem, Payer traz uma citação de Pêcheux que reproduzimos abaixo, no intuito de ilustrar nossas colocações a respeito dos gestos de interpretação do aluno no ritual da prática avaliativa. Diz o autor:

Não entender ou entender errado; não 'escutar' as ordens; não repetir as litanias ou repeti-las de modo errôneo, falar quando se exige silêncio; falar sua língua como uma língua estrangeira que se domina mal; mudar, desviar, alterar o sentido das palavras e das frases; tomar os enunciados ao pé da letra, deslocar as regras na sintaxe e desestruturar o léxico jogando com as palavras... (PÊCHEUX, 1999, p. 17)

Os exemplos de falhas nos rituais, trazidos por Pêcheux, na citação acima, parecem ilustrar não somente a prática avaliativa, mas o cotidiano escolar de forma geral. Diariamente, toda e qualquer tentativa não só por parte do aluno, mas por parte do professor igualmente, de romper com a "normalidade" escolar é entendida como absurdo e, muitas vezes, é ignorada ou silenciada.

\footnotetext{
${ }^{7}$ Anotação usada fraudulentamente como auxílio num exame (Dicionário Priberam da Língua Portuguesa, 2008-2013, http://www.priberam.pt, consultado em 28-08-2015).
} 
Aquilo que é considerado absurdo, no seio da instituição escolar, deveria ser entendido como possibilidade do sentido outro, a abertura do simbólico e, sobretudo, a manifestação da singularidade do sujeito. Como aponta Payer (2012), o absurdo indica, denuncia o "excessivo na/da ordem discursiva" e "reafirma o estatuto de ritual que o discurso encerra" (p. 35). É dessa forma que o absurdo deveria ser ouvido na escola.

Ainda com base no texto de Payer, focaremos, agora, no que ela apresenta sobre a questão da leitura, a partir do mesmo filme. Para isso, a autora recorta uma cena central no filme: um importante personagem que responde pelo nome de Menino ganha um livro de presente de um casal de mambembes. $O$ menino não sabe ler, mas é um atento observador dos acontecimentos de seu entorno e a eles atribui sentido.

O menino estabelece uma relação singular com seu novo objeto simbólico: muito curioso, ele lê a seu modo, inventando histórias, às vezes questionando seu irmão mais velho sobre algo do livro a ponto de irritá-lo. Seu pai também não gosta das histórias que o menino inventa e chega até a tomar o livro de sua mão. Esperto, o menino estabelece relações de sentido entre as figuras do livro e seu entorno. Nesse movimento entre o livro e o contexto, novos sentidos atravessam o menino e, por conclusão:

a entrega de um objeto simbólico como um livro a um menino observador dá início ao que pouco a pouco vai transformar-se em um acontecimento que resultará na desestruturação da ordem discursiva estabelecida em torno dos sujeitos personagens (PAYER, 2012, p. 37).

Payer, então, considera que a leitura de um livro e, acrescentaríamos, a leitura em geral, pode deflagrar acontecimentos discursivos, provocar deslizamentos de sentidos, como a leitura do menino, que a autora diz ser repleta de efeitos metafóricos, que, segundo Orlandi (2007), são efeitos próprios à ordem do simbólico, da ideologia, da historicidade.

As considerações de Payer sobre a leitura sustentam que ler não é resgatar um sentido previamente estabelecido nem depende apenas de fatores cognitivos internos à mente do sujeito, mas, como a própria autora coloca, ler é "deslizar por rios caudalosos da metáfora, mergulhar em deslocamentos que tanto a leitura quanto a arte podem proporcionar" (PAYER, 2012, p. 44). Mas, como os sentidos são regidos sóciohistoricamente e qualquer tentativa de fugir daquilo que é posto, como bem colocado pelo filme, é passível de punição, em todo processo de leitura, principalmente no ambiente escolar, há silenciamento de sentidos.

Trazemos, agora, exemplos de silenciamento da tentativa de produção de sentidos outros pelos alunos, na avaliação. Partindo da questão 10: What sport does Ray practice? (Qual esporte Ray pratica?) um aluno responde really palavra que se assemelha foneticamente a rally - competição automobilística - também um esporte. O mesmo aluno responde na questão 12) What is the danger about this sport? (Qual é o perigo em relação a este esporte): Diving isn't really that dangerous (mergulho não é assim tão perigoso), afirmação que o próprio entrevistado (Ray) fornece na entrevista. Em ambas as respostas, o aluno produz sentidos que não vão ao encontro do que já está estabelecido como correto e, portanto, tem seus sentidos silenciados, o que resulta em uma nota abaixo 
da média $(1,3)$. Há, na resposta deste aluno, a presença do discurso lúdico, ligado ao nonsense, ao chiste, mas não considerado, apagado pelo discurso autoritário.

Parece-nos que a leitura escolar se relaciona com controle, medição, averiguação. A escola e os órgãos governamentais em geral utilizam avaliações externas e internas como instrumentos de matematização da leitura: aplica-se a prova, faz-se um levantamento do resultado, classificam-se as escolas e os alunos, tabula-se o "nível" de leitura dos alunos para, em seguida, tomar medidas reparadoras. Nossa crítica sustenta-se na afirmação de que há algo de incontrolável na leitura, algo de um impossível próprio à língua que não se matematiza e que tem a ver com o conceito de real, entendido como "um impossível da língua", "lugar singular - que admite a falta e a torna constitutiva da estrutura" (FERREIRA, 2000, p. 26).

Nossas palavras finais, a respeito deste exercício analítico, ecoam na crítica que Orlandi (1998) estabelece sobre a identidade linguística escolar: "o que se tem buscado, nos projetos escolares, é a chamada "competência técnica" ou seus similares, ou seja, é a racionalização da repetição formal. ${ }^{8} O$ melhor aluno é o que (re)produz melhor os enunciados do ponto de visto formal" (p. 209, grifos nossos).

Colocando de outra forma, o aluno é visto apenas como um repetidor do conhecimento transmitido em sala de aula e quanto mais ele se distancia deste conhecimento mais negativamente ele é avaliado. Suas representações a respeito de língua e avaliação sugerem um saber exclusivamente escolar, aquele que se encontra apenas na escola, um saber mecanizado, e desvincula-se da realidade em que vivem. Mas, como dissemos, essas representações, que se materializam na língua, são também a denúncia de uma prática escolar que nega o lugar do equívoco, impedindo que a língua faça sentido para o aluno, negando o lugar mesmo da memória discursiva.

\section{Considerações finais}

Nosso objetivo principal, neste trabalho de pesquisa, foi refletir sobre o funcionamento e o efeito da memória discursiva, a partir de um importante aspecto que compõe o processo de ensino-aprendizagem de língua estrangeira (inglês): a avaliação formal escrita, em uma escola regular pública.

Retomando, nossa hipótese inicial de pesquisa, qual seja, que professores e alunos possuem noções de língua distintas, além de uma relação singular com a língua(gem), que afeta a relação ensino-aprendizagem e as práticas avaliativas e produz equívocos nas respostas e interpretações; equívocos estes que não costumam ser trabalhados por professores e alunos, mas sim apagados, silenciados, já que a língua é geralmente representada, no contexto escolar, como algo neutro e possível de ser instrumentalizável, percebemos, ao término deste estudo, que a mesma se sustenta. A sustentação de nossa

\footnotetext{
${ }^{8}$ Repetição formal é o que Orlandi entende como "técnica de produzir frases, exercícios gramaticais que não historicizam, não fazem trabalhar a ligação do sujeito com a memória discursiva" (ORLANDI, 1998, p. 208).
} 
hipótese baseia-se em algumas conclusões a que chegamos, após a análise do corpus discursivo. São elas:

À luz da teoria do discurso, percebemos a impossibilidade de o sujeito-aluno de língua estrangeira desvincular-se de sua língua materna no contato-confronto com uma língua outra. Traços de sua língua primeira estarão presentes na tentativa de produção de sentidos na língua que se busca aprender ou apreender. Esses traços apontam para a relação do sujeito-aluno com sua língua materna e sua representação do que seja uma língua estrangeira, bem como a tentativa de inscrição do sujeito-aluno nesta língua outra. O saber do sujeito-aluno sobre línguas, a sua língua materna e a estrangeira com a qual tem contato, nunca é equivalente. Seu conhecimento sobre/na língua materna, no caso da avaliação aqui especificada, sempre será maior que seu saber em língua estrangeira.

Percebemos que, não apenas na sala de aula de língua estrangeira (inglês), mas na aula de língua materna/portuguesa, na escola regular pública, a visão de língua que prevalece é a de sistema de signos cujo sentido encerra-se em si mesmo, uma estrutura neutra, em que o trabalho da história e da ideologia não é considerado. Essa visão é percebida principalmente na aula de leitura em inglês.

Observamos, em nossa análise, pouca familiaridade do sujeito-aluno com o texto em língua inglesa. Embora a avaliação contenha um texto a ser lido, o saber discursivo do aluno leva-o a responder a ela como um exercício descontextualizado de repetição e memorização que nos remete às práticas do Método Audiolingual. Somos levados a questionar como acontece o trabalho com a língua e o texto em sala de aula.

A análise nos permite argumentar que, durante a prática avaliativa, mais especificamente na leitura do texto, o funcionamento da memória discursiva não se reduz aos conhecimentos linguísticos do aprendiz da/na língua outra, em outras palavras, não é apenas o saber em língua inglesa que é colocado em jogo na avaliação e na leitura, mas sim todo o seu saber discursivo escolar e não escolar. O saber do aprendiz rompe os limites de uma disciplina.

Dessa forma, questionamentos surgem a respeito da avaliação formal na escola regular como, por exemplo: de que maneira pode-se avaliar o sujeito-aluno, levando-se em conta a perspectiva discursiva, uma perspectiva que considera a língua não como sistema fechado, mas sujeita a falhas e ao gesto de leitura atravessado pelo equívoco? Até o momento, com base na análise aqui empreendida, podemos dizer que a avaliação ainda é um instrumento usado pelo professor para controle de disciplina ou como forma de atestar seu poder e que, conforme sugere nossa hipótese, busca silenciar os equívocos e contradições que se mostram significativos para promover deslocamentos no processo de ensino-aprendizagem. Ao desvincular a leitura da obtenção de nota para ser aprovado, por exemplo, a escola pode lançar um novo olhar para a avaliação, um olhar, como dissemos anteriormente, voltado para o discurso polêmico, assim pensado por Orlandi (2011), que prevê a abertura para o sentido outro.

Concluímos que o resultado de uma avaliação, seja positivo ou negativo, deve possibilitar reflexões para o professor e para o aluno, uma vez que o insucesso deste 
último aponta não apenas para o desconhecimento da matéria escolar, mas também para práticas simplistas de ensino às quais ele é submetido. Um trabalho de ensino de línguas significativo passa pela compreensão do professor e do aluno sobre suas representações de língua(gem), texto e avaliação.

E para finalizar, pensando na relação da memória discursiva com a produção de sentidos, concordamos com Orlandi (1998), quando diz que o que faz a língua significar para o sujeito, fazendo com que ele, ao mesmo tempo, se signifique, é a repetição histórica, "aquela que inscreve o dizer no repetível enquanto memória constitutiva, saber discursivo, em uma palavra interdiscurso" (p. 108). É no domínio da repetição histórica que o sentido faz sentido para o discurso do sujeito.

\section{Referências bibliográficas}

CAVALLARI, J.S. O discurso avaliador do sujeito-professor na constituição da identidade do sujeito-aluno. Tese. Doutorado em Linguística Aplicada, Instituto de Estudos da Linguagem, Universidade Estadual de Campinas, Campinas, SP, 2005.

FERREIRA, M.C.L. Da ambiguidade ao equívoco: a resistência da língua nos limites da sintaxe e do discurso. Porto Alegre: Ed. da UFRGS, 2000.

HALL, S. (Ed.). Representation: cultural representations and signifying practices. Nova York: Sage Publications, 1997.

GRIGOLETTO, M. Representação, Identidade e Aprendizagem de Língua Estrangeira. Em: CORACINI, M.J.C. (Org.). Identidade e Discurso: (des)construindo subjetividades. Campinas: Editoda da Unicamp, 2003. p. 223-235.

MILNER, J.C. O Amor da língua. Campinas, SP. Editora da Unicamp, 2012.

MOTTA, V.R.A.; TURRA, B.M. Em matéria de ensino de língua, o método pode faltar. Revista DisSol, Pouso Alegre, v. 1, 1-10, out/2014.

ORLANDI, E.P. A Linguagem e o seu funcionamento: as formas do discurso. $6^{\mathrm{a}}$. ed. Campinas, SP: Pontes, 2011. 2010 .

Análise do discurso: princípios e procedimentos. $10^{\text {a }}$. ed. Campinas, SP: Pontes,

Interpretação; autoria, leitura e efeitos do trabalho simbólico. Campinas, SP: Pontes, 2007.

Identidade Linguística Escolar. Em: SIGNORINI, I. (Org.) Língua(gem) e identidade. São Paulo: Mercado de Letras, 1998. p. 203-211. 
PAYER, M.O. Memória da língua. Imigração e Nacionalidade. São Paulo: Escuta, 2006.

A leitura em Abril Despedaçado: equívoco, deslocamento, acontecimento. Em: CARROZZA, G.; SANTOS, M.; SILVA, T.D. da (Orgs). Sujeito, Sociedade, Sentido. Campinas, Editora RG, 2012. p. 29-44.

PÊCHEUX, M. (1969). Análise automática do discurso. Em: GADET, F. \& HAK, T. (Orgs.). Por uma análise automática do discurso: uma introdução à obra de Michel Pêcheux. 5a . ed. Campinas, SP: Unicamp, 2014. p. 59-158.

Delimitações, Inversões, Deslocamentos. Cadernos de Estudos Linguísticos, $\mathrm{n}^{\circ}$ 19, IEL, Unicamp, 1999.

Artigo recebido em: setembro de 2016.

Aprovado e revisado em: dezembro de 2016.

Publicado em: abril de 2017.

\section{Para citar este texto:}

FRANCO, Wagner Ernesto Jonas. O funcionamento da memória discursiva e o equívoco na prática avaliativa de língua inglesa. Entremeios [Revista de Estudos do Discurso, online], Seção Temática - Língua(gem) e Ensino, Programa de Pós-Graduação em Ciências da Linguagem (PPGCL), Universidade do Vale do Sapucaí (UNIVÁS), Pouso Alegre (MG), vol. 14, p. 185-201, jan. - jun. 2017.

DOI: http://dx.doi.org/10.20337/ISSN2179-3514revistaENTREMEIOSvol14pagina185a201 